\title{
Design and Modeling of Vacuum Pumping for Steady-State Pellet Fueling Systems
}

\author{
T. E. Gebhart ${ }^{1}$, D. Shiraki ${ }^{1}$, J. Baldzuhn ${ }^{2}$, L. R. Baylor ${ }^{1}$, and S. J. Meitner ${ }^{1}$
}

1. Oak Ridge National Laboratory, Oak Ridge, Tennessee, USA

2. Max Planck Institute for Plasma Physics, Greifswald, Germany

gebhartge@ornl.gov

\section{Address for Correspondence:}

Oak Ridge National Laboratory ATTN: Trey Gebhart

PO BOX 2008

Building 5600 MS 6169

Oak Ridge, TN, 37831

Manuscript Length:

14 Pages (Not including cover sheet)

3 Tables

8 Figures

Notice of Copyright: "This manuscript has been co-authored by UT-Battelle, LLC, under contract DE-AC05000R22725 with the US Department of Energy (DOE). The US government retains and the publisher, by accepting the article for publication, acknowledges that the US government retains a nonexclusive, paid-up, irrevocable, worldwide license to publish or reproduce the published form of this manuscript, or allow others to do so, for US government purposes. DOE will provide public access to these results of federally sponsored research in accordance with the DOE Public Access Plan (http://energy.gov/downloads/doe-public-accessplan)." 


\section{Design and Modeling of Vacuum Pumping for Steady-State Pellet Fueling Systems}

T. E. Gebhart ${ }^{1}$, D. Shiraki ${ }^{1}$, J. Baldzuhn ${ }^{2}$, L. R. Baylor ${ }^{1}$, and S. J. Meitner ${ }^{1}$

1. Oak Ridge National Laboratory, Oak Ridge, Tennessee, USA

2. Max Planck Institute for Plasma Physics, Greifswald, Germany

Abstract - Future long-pulse magnetic confinement fusion reactors will require density and isotopic mixture control using steady-state repeating pellet injectors. For high energy density burning plasmas, pellet velocities of $1 \mathrm{~km} / \mathrm{s}$ and above will be required for sufficient plasma penetration to achieve high fueling efficiency. Currently, steady-state repeating injection systems utilize cryogenic extruder systems to produce an extrusion of solid deuterium or deuterium-tritium. In repeating light gas gun injectors, the solid extrusion is cut and simultaneously loaded into a barrel. Once loaded, a fast operating gas valve delivers a high pressure burst of gas to accelerate the pellet down the barrel and into the machine. This process takes $\sim 10 \mathrm{~ms}$ to achieve. Adequate gas pumping of the extruder exhaust and injection line propellant gas collection chambers is necessary for optimal operation of the pellet fueling system. Excess solid from the extruder sublimates in an exhaust chamber. The gas pressure in the extruder exhaust chamber must remain low to maintain low heating loads on the cooling mechanism (cryo-refrigerators or liquid helium flow) and to reduce thermal conduction to the extrusion. Pumping the injection line chambers is necessary to limit propellant gas flow into the machine. A numerical simulation code was created to predict temporal pumping performance for these repeating pellet injection systems. This paper will outline the methods and assumptions used to create this model and compare results to the pellet injection system currently employed on DIII-D, the steady-state pellet injection system planned for Wendelstein 7-X, and a brief analysis of the ITER conceptual pellet fueling system.

Keywords- Vacuum Pumping, Fusion Fueling, Pellet Injection 


\section{INTRODUCTION}

Future long-pulse magnetic confinement fusion reactors, such as ITER or DEMO, will require the injection of deuterium $\left(\mathrm{D}_{2}\right)$ or deuterium-tritium (DT) pellets at a rate of $10 \mathrm{~Hz}$ or more [1,2]. These pellet injection systems will be used as part of an active feedback control system to regulate core densities [3]. Pellets with speeds greater than $1,000 \mathrm{~m} / \mathrm{s}$ will likely be required for high energy density fusion reactor plasmas to ensure adequate penetration into the core. Similar pellet injection systems may be used for edge localized mode (ELM) mitigation, where high frequency $(30-60 \mathrm{~Hz})$ pellets can be injected from the low field side (LFS) into the plasma edge [4]. Various types of pellet injection systems are currently used throughout the world. The most common are repeating light gas guns and centrifuges. The centrifuge rotates an acceleration arm at a high frequency that can accelerate pellets cut from an extrusion to high speeds, $>1000 \mathrm{~m} / \mathrm{s}$ [5], without the use of propellant gas, which is an advantage compared to the light gas gun approach. The light gas gun steady-state pellet injection system consists of an extruder that produces a steady stream of solid $\mathrm{D}_{2}$ or DT, a gun mechanism that cuts, chambers, and fires the pellet, and a downstream series of ballast volumes. Pellets are accelerated using a solenoid-driven fast opening gas valve [6] that provides a pulse of high pressure light gas $\left(\mathrm{He}, \mathrm{D}_{2}\right.$, or $\left.\mathrm{H}_{2}\right)$ to the rear of the pellet. Systems of this type are currently used on the Joint European Torus (JET), Large Helical Device (LHD), and DIIID for high frequency pellet fueling and ELM mitigation experiments $[7,8,9]$. A basic schematic of a repetitive steady-state gas gun pellet injection system is shown in Figure 1.

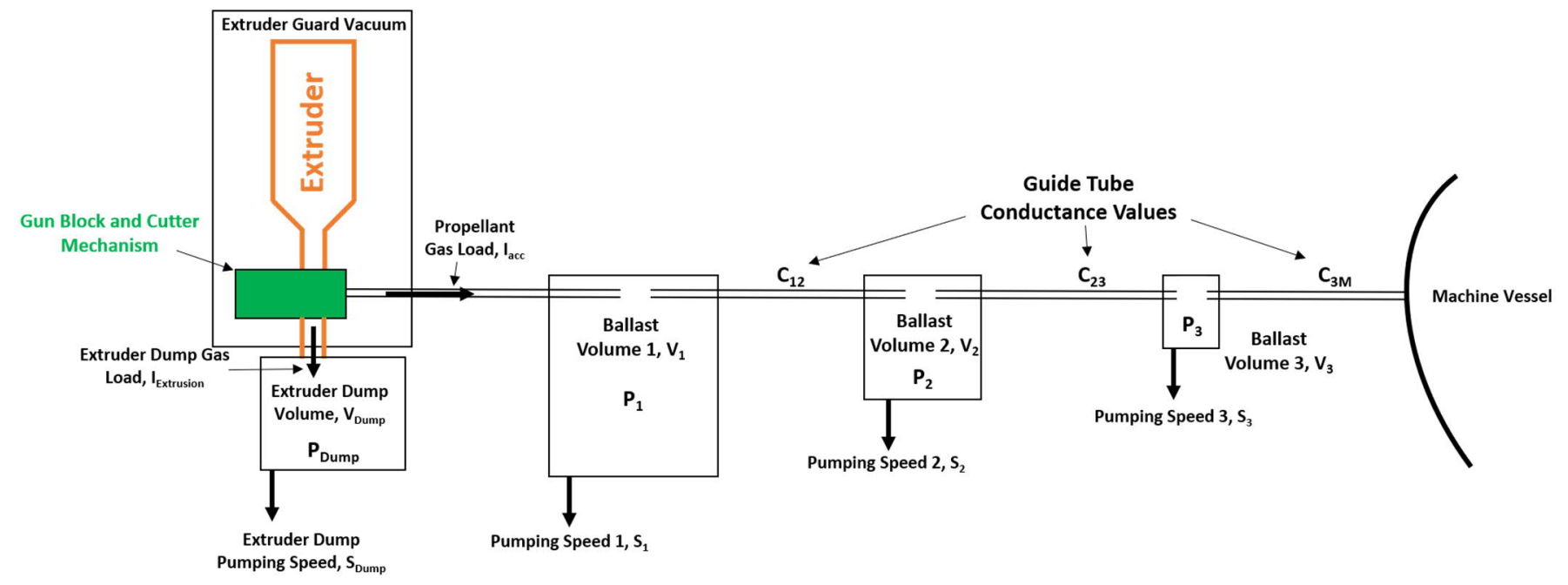

Fig. 1. A general schematic of a steady-state high frequency gas gun pellet injector and downstream ballast volumes.

The amount of propellant gas needed to achieve high speed pellets at a high frequency is substantial and its flow into the plasma chamber must be kept to a low rate. The propellant gas is collected by pumping on downstream ballast volumes that are located at gaps in the injection line guide tubes. In the example in Fig. 1, three volumes are used to collect and pump this propellant gas load. 
The most common form of pumping is through the use of mechanical vacuum pumps, although, cryopumps have been used in the past [10]. Governing equations originally presented by Sakamoto et. al. [8] for the pressures in these three volumes are:

$$
\begin{aligned}
& V_{1} \frac{d P(t)_{1}}{d t}=I_{a c c}+C(t)_{12}\left(P(t)_{2}-P(t)_{1}\right)-S(t)_{1} P(t)_{1}+L_{1} \\
& V_{2} \frac{d P(t)_{2}}{d t}=C(t)_{12}\left(P(t)_{1}-P(t)_{2}\right)+C(t)_{23}\left(P(t)_{3}-P(t)_{2}\right)-S(t)_{2} P(t)_{2}+L_{2} \\
& V_{3} \frac{d P(t)_{3}}{d t}=C(t)_{23}\left(P(t)_{2}-P(t)_{3}\right)-S(t)_{3} P(t)_{3}+L_{3}
\end{aligned}
$$

where $P_{1}, P_{2}$, and $P_{3}$ are the pressures in associated volumes $V_{1}, V_{2}$, and $V_{3}$. $I_{\text {acc }}$ is the gas load from the pellet propellant gas. $C_{12}$ and $\mathrm{C}_{23}$ represent the conductance values for gas flow between Volumes 1 and 2 and Volumes 2 and $3 . S_{1}, S_{2}$, and $S_{3}$ are the pressure dependent pumping speeds for the pumps attached to the corresponding stages, and $\mathrm{L}_{1}, \mathrm{~L}_{2}$, and $\mathrm{L}_{3}$ are assumed leak rates for the vacuum components associated with each volume. In this work, the conductances and pumping speeds are functions of pressure and therefore are time dependent unlike the earlier published simulations [8].

This system of equations was coded in Python using a fourth order Runge-Kutta routine [11,12]. The fourth order Runge-Kutta method uses approximations for the slope at four points within the time step and averages these four approximations, weighing the two midpoint increments higher than the beginning or end increments. The stability region of this fourth order trapezoidal solver is calculated within the code. Stability of the Runge-Kutta solver is dependent on the ratio of the step size to the magnitude of change of each function in the system. Keeping the time step small is necessary to ensure stability through large transients in the simulation. The time step for these simulations is kept constant at $1 \times 10^{-6}$ seconds. A similar routine was written for the single-equation extrusion dump pressure. The pressure in the extruder exhaust chamber (dump) can be expressed as;

$$
V_{\text {Dump }} \frac{d P(t)_{\text {Dump }}}{d t}=I(t)_{\text {Extrusion }}-S(t)_{\text {Dump }} P(t)_{\text {Dump }}
$$

where $\mathrm{V}_{\text {Dump }}, \mathrm{P}_{\text {Dump }}, \mathrm{I}_{\text {Extrusion, }}$ and $\mathrm{S}_{\text {Dump }}$ are the volume of the extruder dump, the pressure in the extruder dump volume, the gas load from the extrusion stream, and the pumping speed of the pumping unit connected to the extruder dump. This equation is solved using the same Runge-Kutta method described above. The importance of this model is to determine the steady-state operating pressure of the extruder dump volume and determine if the associated pumps can maintain pressures $<1$ bar during a full-volume dump of the extruder material. A low steady-state pressure in the extruder dump volume will limit thermal conduction to cryogenically cooled components, which will limit the heat load on the cooling system. During a loss of cooling scenario, the solid 
material generated within the extruder will flash to gas and could possibly result in very high pressures in the extruder dump (depending on the volume of the dump). Maintaining a peak transient pressure of $<1$ bar is necessary for two reasons; component longevity and to comply with pressure guidelines for hydrogen at the research laboratories where they are used.

Some injector systems combine pumping of the extruder dump with the first ballast volume, which results in a combined gas load and a convolution of Equations 1 and 2. The new governing equation for the pressure in the first volume is;

$$
V_{1+\text { Dump }} \frac{d P(t)_{1+\text { Dump }}}{d t}=I(t)_{\text {Extrusion }+ \text { acc }}-C(t)_{12}\left(P(t)_{2}-P(t)_{1+\text { Dump }}\right)-S(t)_{1} P(t)_{1+\text { Dump }}+L_{1}
$$

where the subscript $1+$ Dump refers to the combined volume of the extruder dump combined with the first stage ballast volume. $I_{\text {Extrusiontacc }}$ is the combined gas flow of the propellant gas and the extrusion exhaust $\left(I_{\text {acc }}+I_{\text {Extrusion }}\right)$. The schematics of combined pumping of the first ballast volume and the extruder dump are shown in Figure 2.

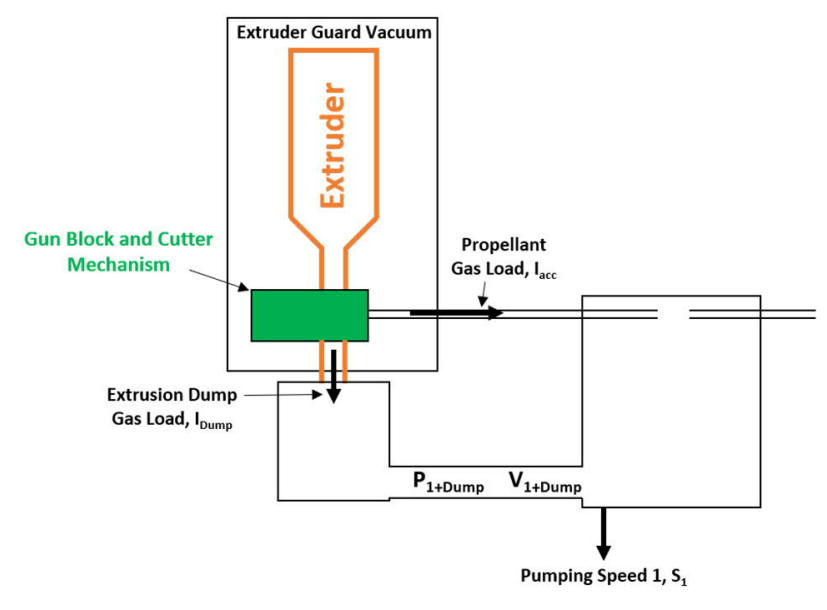

Fig. 2. Schematics of a pumping system which combines the extruder dump and first stage ballast volume pumping.

The remainder of this paper will discuss the specific methods and assumptions made when solving the above system of equations, a realistic validation using parameters from the DIII-D repetitive pellet injector, preliminary conceptual design of the vacuum system for the Wendelstein 7-X (W7-X) steady state pellet injection system, and a brief analysis of the conceptual ITER pellet fueling system.

\section{Modeling Ballast Volume Pressure}

The pressure in the three ballast volumes is essentially a balance between incoming propellant gas and the ability of the chosen vacuum pumps to exhaust the incoming gas. To model the ballast volume pressures, geometrical parameters of the system must be accurately known. The size of each volume and the lengths and diameters of each guide tube section are the most important. The size of each volume affects the dynamics of the system by changing how rapidly a steady state pressure is reached. For example, if 
a volume is large, it would take longer to reach its steady state pressure. Conductance values influence the rate at which gas can flow between volumes, and more importantly, into the plasma chamber. These values are pressure dependent. The pressure dependency of the conductance is driven by the type of flow regime experienced for the range of pressures within the system. Laminar flow, Knudsen flow, and molecular flow are the types of flow regimes that occur at the pressure ranges experienced in these systems. Conductance values are calculated using the Knudsen equation. The Knudsen equation is normally valid for air but can be modified for flow of the helium or other gasses by applying a correction factor [13]. Although this is a two-gas system (He and $\mathrm{D}_{2}$ ), the assumption is made that helium is the only gaseous material flowing through the guide tubes. It is assumed that the fuel material remains primarily in solid form and that the extruder exhaust is adequately pumped. The Knudsen equation is given by;

$$
C=135 \frac{d^{4}}{l} \bar{P}+12.1 \frac{d^{3}}{l} \cdot \frac{1+192 \cdot d \cdot \bar{P}}{1+237 \cdot d \cdot \bar{P}}(L / s)
$$

W

$\mathrm{h}$

e

$\mathrm{r}$

e

C

i

S

$$
I(t)_{a c c}=A \sin (\omega t)+A
$$

that, when integrated, provides a gas flow of approximately $10 \%$ of $\mathrm{A}$ at a frequency of $10 \mathrm{~Hz}\left(\omega=2 \pi^{*} 10\right)$. In Equation 5 , A is an $\mathrm{t}$ amplitude (A/10 is the desired gas load per shot at $\left.\omega=2 \pi^{*} 10\right), \omega$ is a frequency, and $\mathrm{t}$ is time.

$\mathrm{h}$ The Python code is structured so that initial conditions for pressure are the only input besides constant system geometry. For pellet injector systems in general, the initial pressure in all three stages is assumed to be $1 \times 10^{-7}$ mbar. The initial pressure is used to define the initial pumping speed for each stage and initial conductance values between stages. Once the initial values are set, the equations c are solved within a for-loop, each iteration of the for-loop being a time step. As the code steps through the for-loop, it calculates o pressure for the next time step, which is then used to calculate pumping speeds and conductance values for the next time step as n well. As these values are calculated, they are stored in an array. The arrays are used to plot the pressures, pumping speeds, and $\mathrm{d}$ 
conductance values for the specified time duration. Along with plots, the code calculates the gas flow out of the final stage into the plasma chamber based on the pressure in the third stage.

\section{Modeling Extruder Dump Pressure}

To model the extruder dump pressure separately from the downstream volumes, the same Runge-Kutta for-loop structure is used. To determine whether pumping is sufficient to handle a full-volume dump of the extruder, the gas load, $\mathrm{I}_{\text {Extrusion, }}$, is changed based on trends seen in previous extruder laboratory tests. Figure 3 shows the pressure spike measured during a full-volume dump of a twin-screw extruder. Approximately 77.5 bar- $\mathrm{L}$ of $\mathrm{D}_{2}$ was dumped during this warm up event. The warm up is not instantaneous and therefore the dump takes over $\sim 50$ seconds and the pressure reaches a maximum of $\sim 475 \mathrm{mbar}$ in the $\sim 10 \mathrm{~L}$ dump volume. The outflow from the extruder is not constant during the dump but is approximated in the code as a constant flow. The code approximates the transient phenomenon by increasing the gas load to an average value for a specific duration, normally denoted by the amount of gas in the extruder (in mbar-L) divided by the approximate time in which a full-volume dump occurs. To simulate steady state extruder operation, the code uses a gas load based on the maximum extruder throughput, minus the gas inventory of the pellets that are accelerated out of the barrel.

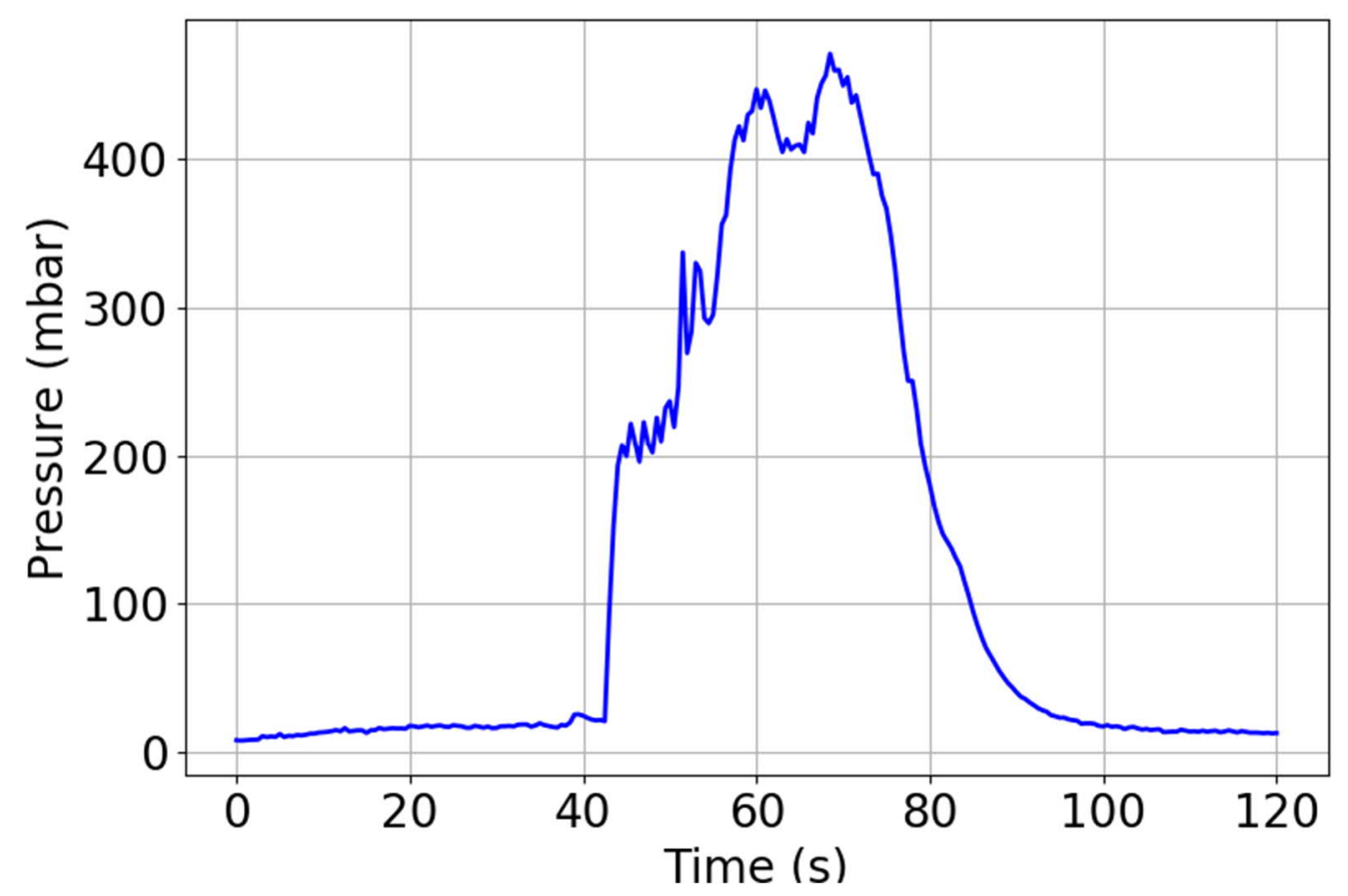

Fig. 3. A plot showing the pressure in a $\sim 10 \mathrm{~L}$ extruder dump volume during a full-volume extruder dump caused by a loss of cooling thermal runaway. 


\section{ResUlts AND Discussion}

The code was benchmarked against the results in the work by Sakamoto [8] by keeping the pumping speeds and conductance values constant as was reported in this work. The current repetitive DIII-D pellet injector was also used to validate the code. The DIII-D

system parameters are listed in Table 1 . This test was conducted with a gun that is only connected to the $1^{\text {st }}$ and $2^{\text {nd }}$ ballast volumes and bypasses the third ballast volume to the torus isolation valve. Pellet strings were fired for 5 second durations at 5 Hz. The propellant valve is held open for $1.3 \mathrm{~ms}$, which translates to an approximate gas load of 12.3 mbar- $\mathrm{L}$ per shot (as measured experimentally). The maximum pressure seen in the $2^{\text {nd }}$ stage after five seconds was $8.3 \times 10^{-5}$ mbar $\left(6.2 \times 10^{-5}\right.$ Torr $)$. This test was conducted with no gas load from the extruder into the $1^{\text {st }}$ stage ballast volume. The pump used for the $1^{\text {st }}$ stage is a Varian TV 301 NAV turbo pump backed by a large rotary vane pump $\left(\sim 50 \mathrm{~m}^{3} / \mathrm{h}\right)$. The $2^{\text {nd }}$ stage uses a Pfeiffer TPU $180 \mathrm{H}$ turbo pump and the $3^{\text {rd }}$

stage 3 uses a Pfeiffer TPU 062H turbo pump, although the $3^{\text {rd }}$ stage pump was not used in this validation test. The $2^{\text {nd }}$ and $3^{\text {rd }}$ stage turbos are backed by a common rotary vane pump with a pumping speed of $\sim 50 \mathrm{~m}^{3} / \mathrm{h}$. The schematics for this system are shown in Figure 4. Fits for these pumping speed curves were put into the code and used to ensure the accuracy of the results. Figure 5 shows a temporal plot of the calculated pressures in the $1^{\text {st }}$ and $2^{\text {nd }}$ stages, and a comparison with the experimental results. Since there is no extruder dump load, the equations in Equation 1 are sufficient for this scenario. To get an input gas load, $\mathrm{I}_{\mathrm{acc}}$, of $\sim 12 \mathrm{mbar}-\mathrm{L} / \mathrm{shot}$ at $5 \mathrm{~Hz}, \mathrm{~A}$ and $\omega$ are set as 60 and 31.4 , respectively. The code predicts the pressure in the $2^{\text {nd }}$ stage to be $9.4 \times 10^{-5}$ mbar after five seconds of operation. The DIII-D injector is designed to operate for $<10$ seconds so steady state pressures are never reached. Only the $2^{\text {nd }}$ stage pressure is available experimentally. 


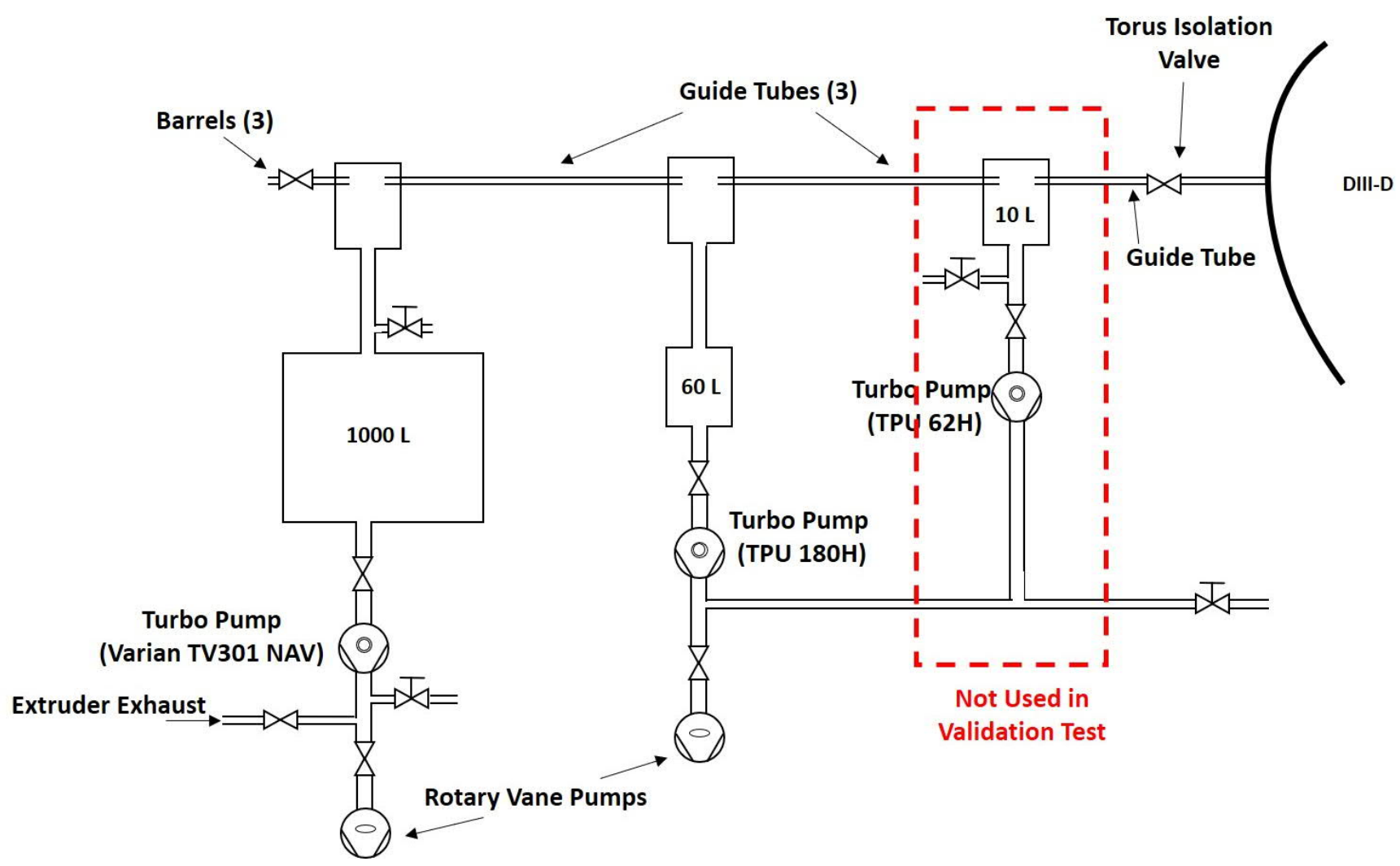

Fig. 4. A schematic of the currently used DIII-D Pellet injection vacuum system.

Table 1. Physical parameters of the DIII-D pellet injection vacuum system.

\begin{tabular}{|l|c|}
\hline Volume 1 & $1000 \mathrm{~L}$ \\
\hline Volume 2 & $60 \mathrm{~L}$ \\
\hline Volume 3 & $10 \mathrm{~L}$ \\
\hline Drift Tube Diameter (Stage 1-2) & $0.63 \mathrm{~cm}$ \\
\hline Drift Tube Diameter (Stage 2-3) & $3 \mathrm{~cm}$ \\
\hline Drift Tube Diameter (Stage 3-machine) & $4 \mathrm{~cm}$ \\
\hline Drift Tube Length (Stage 1-2) & $33 \mathrm{~cm}$ \\
\hline Drift Tube Length (Stage 2-3) & $310 \mathrm{~cm}$ \\
\hline Drift Tube Length (Stage 3-machine) & $100 \mathrm{~cm}$ \\
\hline Initial Pressure of Volumes & $1 \mathrm{E}-7 \mathrm{mbar}$ \\
\hline
\end{tabular}




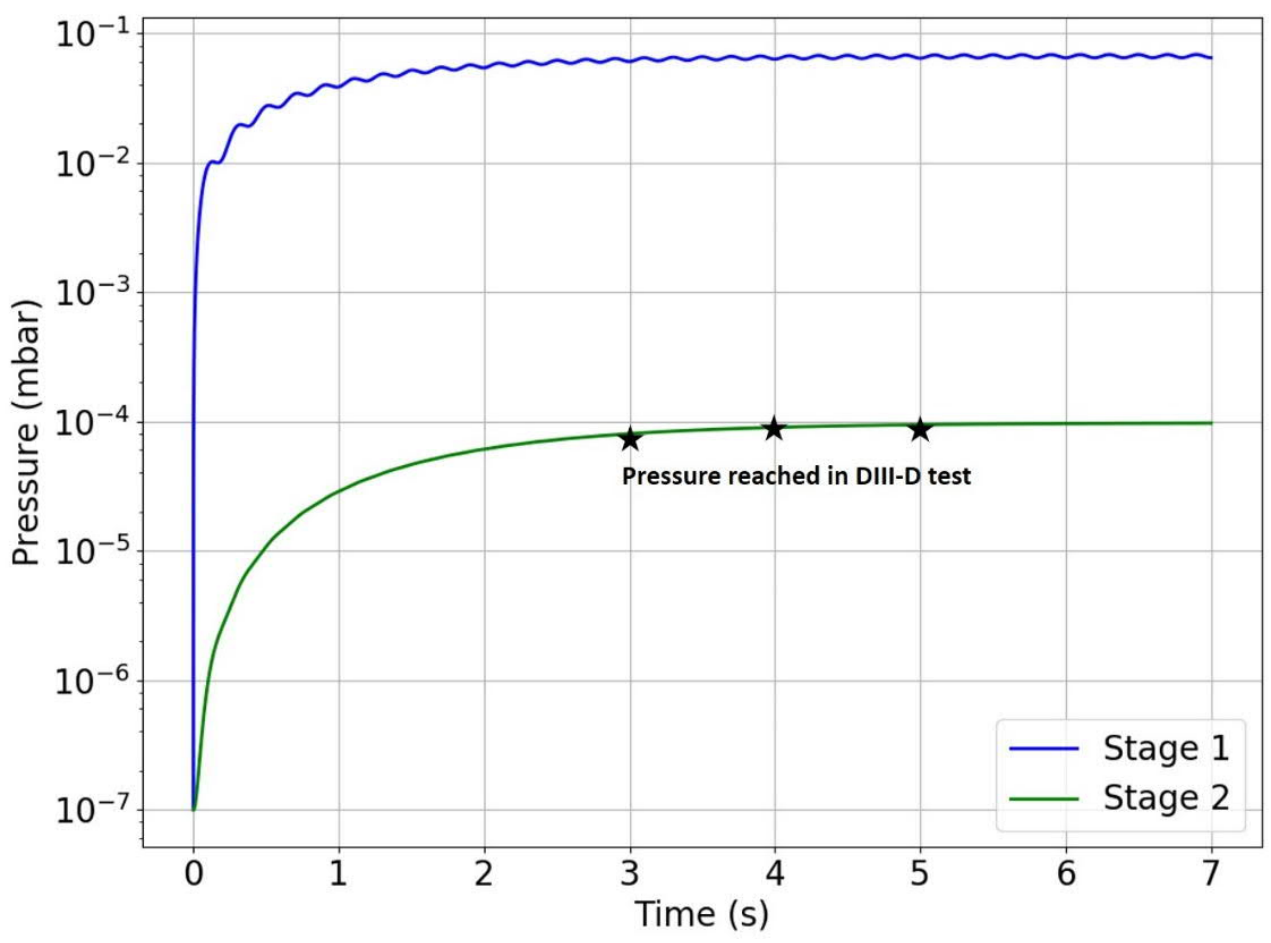

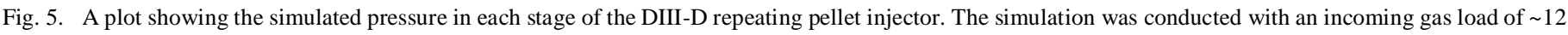
mbar-L/pulse at $5 \mathrm{~Hz}$.

A continuous pellet fueling system is being designed for $\mathrm{H}_{2}$ and $\mathrm{D}_{2}$ operation on W7-X. This analysis only addresses $\mathrm{D}_{2}$ operation. The W7-X injection system will be designed to operate at steady state for up to 30-minute duration plasmas. This paper assumes that the W7-X design will be similar to the DIII-D system and will combine pumping of the extruder dump and the first ballast volume. The pumping system is being designed for the worst-case gas loads, which will consist of a steady solid $\mathrm{D}_{2}$ flow of 0.5 bar$\mathrm{L} / \mathrm{s}$ from the extruder, a propellant gas flow of 0.1 bar-L/pellet at a rate of $10 \mathrm{~Hz}$, and a transient gas flow of 3.2 bar-L/s for a 30 second extruder dump at the end of the 30-minute run. The transient load simulates a dump of the solid held within the extruder and is the worst-case gas load scenario that the W7-X pumping system will encounter. Table 2 shows a list of the parameters of the planned injection line ballast volumes and drift tubes. A Pfeiffer WS 5500 WWH pumping system will pump the first stage and extruder dump. This pumping system consists of three pumps in series; an Okta $6000 \mathrm{M}$ roots pump, an Okta $1000 \mathrm{M}$ roots pump, and a Cobra NS $0600 \mathrm{C}$ dry screw pump. The second and third stages will be pumped by a Pfeiffer HiPace 400 and a Pfeiffer HiPace 80 turbo pump with a molecular drag stage, both backed by a dry roughing pump. Table 3 lists these pumps and their corresponding attributes. These pumping curves were fit and put into the code to accurately predict the steady state operating pressures. Figure 6 shows the results of the simulation run using the W7-X parameters. The steady-state pressures predicted for Stage 1, 2, and 3 are $2.47 \mathrm{mbar}, 1.3 \times 10^{-3} \mathrm{mbar}$, and $3.9 \times 10^{-6} \mathrm{mbar}$, respectively. The pressure in the $3^{\text {rd }}$ stage results in a steady state flow rate of $1.6 \times 10^{-}$ ${ }^{7} \mathrm{mbar}-\mathrm{L} / \mathrm{s}$ of helium into the plasma chamber. 
Table 2. Physical parameters of the proposed W7-X pellet injection vacuum system.

\begin{tabular}{|l|c|}
\hline Volume 1 & $100 \mathrm{~L}$ \\
\hline Volume 2 & $100 \mathrm{~L}$ \\
\hline Volume 3 & $2 \mathrm{~L}$ \\
\hline Extruder Dump Volume & $100 \mathrm{~L}$ \\
\hline Drift Tube Diameter (Stage 1-2) & $0.5 \mathrm{~cm}$ \\
\hline Drift Tube Diameter (Stage 2-3) & $0.65 \mathrm{~cm}$ \\
\hline Drift Tube Diameter (Stage 3-machine) & $0.8 \mathrm{~cm}$ \\
\hline Drift Tube Length (Stage 1-2) & $50 \mathrm{~cm}$ \\
\hline Drift Tube Length (Stage 2-3) & $50 \mathrm{~cm}$ \\
\hline Drift Tube Length (Stage 3-machine) & $400 \mathrm{~cm}$ \\
\hline Initial Pressure of Volumes & $1 \mathrm{E}-7 \mathrm{mbar}$ \\
\hline
\end{tabular}

Table 3. Parameters of pumps listed for the W7-X steady-state pellet injector.

\begin{tabular}{|c|c|c|c|c|}
\hline Pumping System & Pumps & Type of Pump & Injector Stage & $\begin{array}{l}\text { Nominal Helium } \\
\text { Pumping Speed at } \\
50 \mathrm{~Hz} \text { Power }\left(\mathrm{m}^{3} / \mathrm{h}\right)\end{array}$ \\
\hline \multirow{3}{*}{$\begin{array}{l}\text { Pfeiffer WS } 5500 \\
\text { WWH }\end{array}$} & $\begin{array}{l}\text { Pfeiffer O kta } 6000 \\
\text { M }\end{array}$ & Roots Pump & \multirow{3}{*}{$\begin{array}{l}\text { First Stage and Extruder } \\
\text { Dump }\end{array}$} & \multirow{3}{*}{5410 at $1 \mathrm{mBar}$} \\
\hline & Pfeiffer Okta $1000 \mathrm{M}$ & Roots Pump & & \\
\hline & Cobra NS $0600 \mathrm{C}$ & $\begin{array}{l}\text { Dry Screw } \\
\text { Pump }\end{array}$ & & \\
\hline $\begin{array}{l}\text { Single Turbo Backed } \\
\text { by Dry Roughing } \\
\text { Pump }\end{array}$ & Pfeiffer HiPace 400 & Turbo Pump & Second Stage & 1728 at $10^{-3} \mathrm{mBar}$ \\
\hline $\begin{array}{l}\text { Single Turbo Backed } \\
\text { by Dry Roughing } \\
\text { Pump }\end{array}$ & Pfeiffer HiPace 80 & Turbo Pump & Third Stage & 205 at $10^{-3} \mathrm{mBar}$ \\
\hline
\end{tabular}




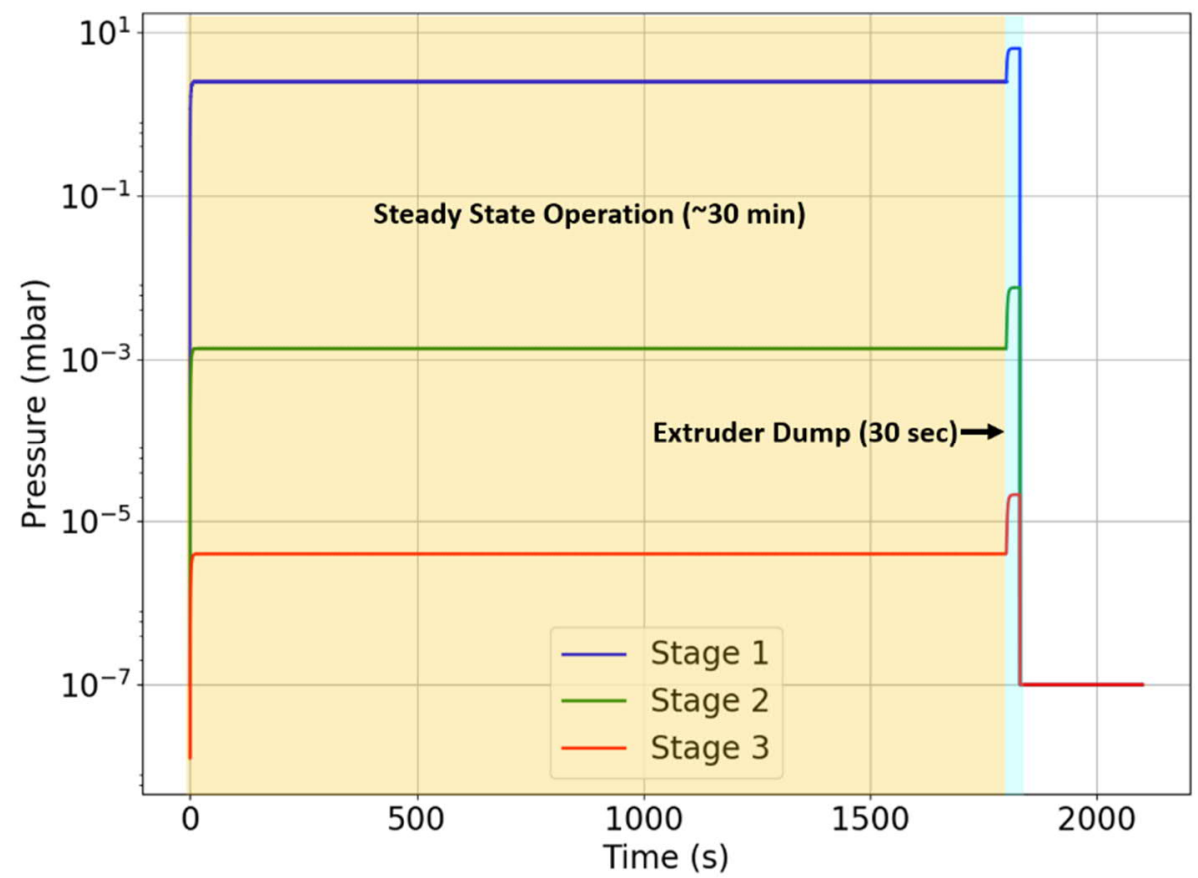

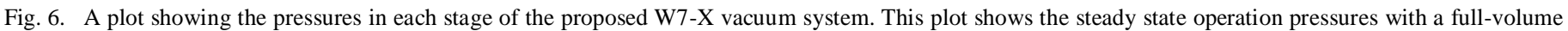
extruder dump at the end of the 30 minute steady state operation.

Failure analysis of the pumping system was conducted to determine the maximum gas load per pellet that the pumping systems will be able to handle at an injection frequency of $10 \mathrm{~Hz}$. A helium propellant load of $>600 \mathrm{mbar}-\mathrm{L} /$ pulse and a steady-state hydrogen/deuterium extrusion load of $500 \mathrm{mbar}-\mathrm{L} / \mathrm{s}$ causes a runaway pressure increase in the pumping system as the turbo pumps on Stages 2 and 3 lose pumping capability. Helium propellant gas flows higher than $120 \mathrm{mbar}-\mathrm{L} / \mathrm{pulse}$ will result in a reduction of pumping efficiency of the first stage, Pfeiffer WS $5500 \mathrm{WWH}$, pump because the pressure in the $1^{\text {st }}$ stage will be greater than 2 mbar. At this pressure the pumping speed of the Pfeiffer WS 5500 WWH starts decreasing rapidly. Although pumping efficiency of the first stage is reduced at propellant loads above $120 \mathrm{mbar}-\mathrm{L} / \mathrm{pulse}$, runaway pressure rise will not occur until propellant gas flows of $600 \mathrm{mbar}-\mathrm{L} /$ pellet are used. Figure 7 shows a plot of the pressures for each stage versus time for sustained propellant loads of $600 \mathrm{mbar}-\mathrm{L} / \mathrm{pulse}$ combined with a steady extrusion (hydrogen/deuterium) load of $500 \mathrm{mbar}-\mathrm{L} / \mathrm{s}$. These gas loads result in a shutdown of the vacuum system after about 170 seconds of operation. Figure 8 shows a plot of the pumping speeds for the pumps on each stage. The collapse in pumping of the $2^{\text {nd }}$ stage results in the collapse of pumping of the $3^{\text {rd }}$ stage. At 1 bar, the Pfeiffer WS $5500 \mathrm{WWH}$ has a nominal helium pumping speed of $650 \mathrm{~m}^{3} / \mathrm{h}$, which is not capable of preventing the pumping collapse of the second and third stages. The for-loop within the code breaks when the pressure in Stage 3 reaches atmospheric pressure $(\sim 1$ bar $)$ to prevent the solver from going unstable. 


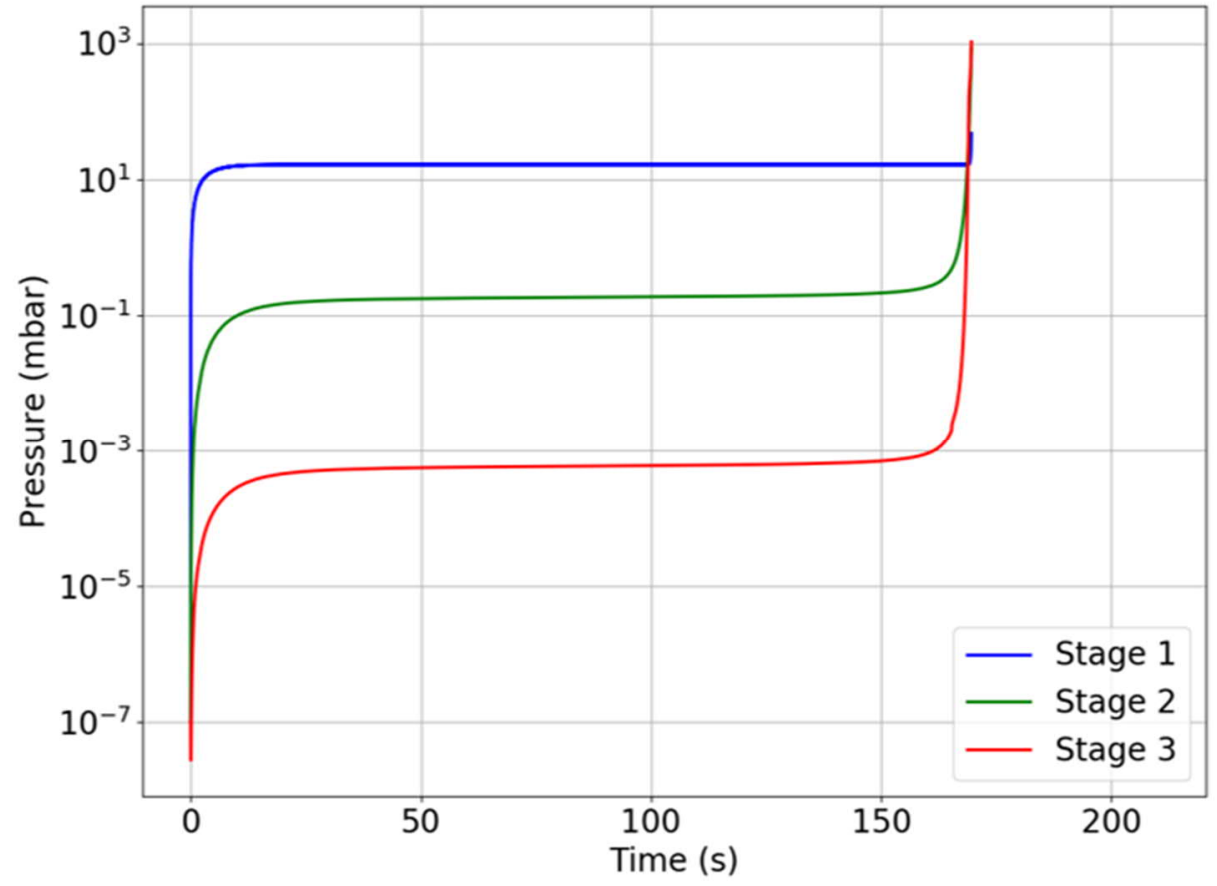

Fig. 7. A plot showing the pressures in each stage for a propellant load of $600 \mathrm{mbar}-\mathrm{L} / \mathrm{pulse}$ and an extrusion load of $500 \mathrm{mbar}-\mathrm{L} / \mathrm{s}$, for the proposed W7-X vacuum system. The drastic increase in pressure is caused by a collapse of pumping in Stages 2 and 3.

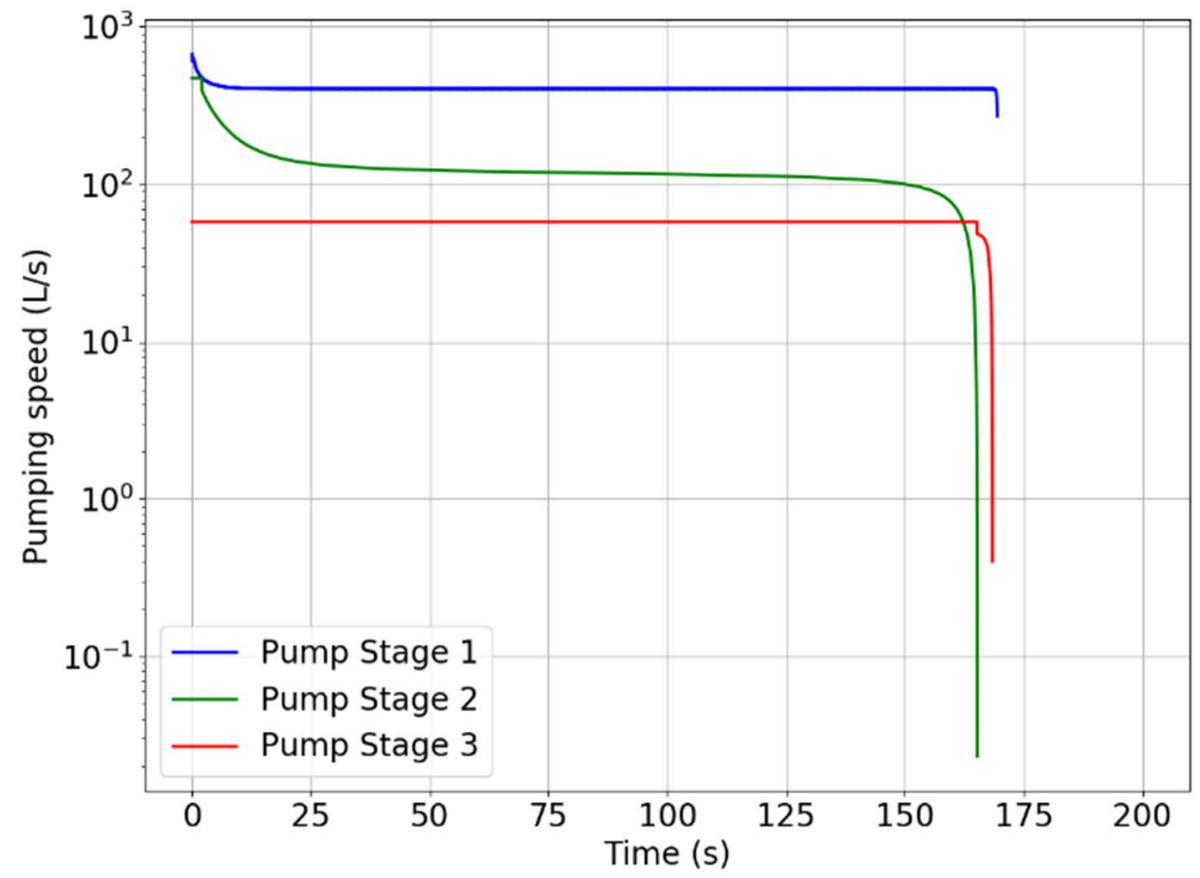

Fig. 8. A plot showing the collapse of pumping speeds of the Stage 2 and 3 pumps of the proposed W7-X vacuum system at $600 \mathrm{mbar}-\mathrm{L} / \mathrm{Pulse}$ at $10 \mathrm{~Hz}$.

The current conceptual design for the ITER steady state pellet fueling system is very similar to the DIII-D and W7-X systems in that it contains three injection line ballast volumes and a pump for each volume [14]. The $1^{\text {st }}$ stage will be pumped by a custom 
tritium compatible piston pump that has a maximum pumping speed of $150 \mathrm{~m}^{3} / \mathrm{h}$ [15]. The second and third stage pumps have not yet been identified. The ITER fueling system will launch fueling pellets at $\sim 4 \mathrm{~Hz}$ at speeds no greater than $300 \mathrm{~m} / \mathrm{s}$ to ensure survivability through the bent guide tubes, which is a much smaller propellant gas load than the high speed W7-X pellet fueling system. Propellant gas loads for the relatively slow ITER fueling pellets is assumed to be $10 \mathrm{mbar}-1 / \mathrm{pellet}$. If the ITER system has the same ballast volume sizes, guide tube geometry, and $2^{\text {nd }}$ and $3^{\text {rd }}$ stage pumps as the W7-X system, the resulting pressure in the $1^{\text {st }}$ stage of the ITER pellet injection system is predicted to be 3.3 mbar, which should be compatible with the gas gun operation.

\section{CONCLUSIONS}

In conclusion, the code can accurately predict pressures within the injection line ballast volumes by incorporating pressure dependent pumping speed curves and conductance values. The test measurements from the DIII-D pellet injection system were used to verify the accuracy of the code. The test yielded a $2^{\text {nd }}$ stage pressure of $8.3 \times 10^{-5} \mathrm{mbar}$ after five seconds of propellant valve pulses at $5 \mathrm{~Hz}$. The code predicted this pressure to be $9.4 \times 10^{-5} \mathrm{mbar}$, which is $\sim 13 \%$ error. Simulations show that the gas loads predicted for the design of the W7-X steady-state pellet injector can be handled while maintaining adequate pressures when using the pumps previously described. The predicted gas loads for normal steady state operation are $100 \mathrm{mbar}-1 / \mathrm{pellet}$ at $10 \mathrm{~Hz}$, plus $500 \mathrm{mbar}-1 / \mathrm{s}$ extruder exhaust. Pumping speed of the Pfeiffer WS 5500 WWH starts to decrease with a propellant gas flow of 120 mbar-1/pellet at $10 \mathrm{~Hz}$, plus $500 \mathrm{mbar}-1 / \mathrm{s}$ extruder exhaust. Although the pumping speed of the $1^{\text {st }}$ stage drops, low vacuum pressure is still maintained. A failure analysis predicts that catastrophic loss of pumping will not occur until a propellant load of $>600 \mathrm{mbar}-1 / \mathrm{pellet}$ is introduced. The probability of delivering this amount of propellant is highly unlikely. Overall, the proposed design of the W7-X steady-state pellet injection vacuum system is adequate for the proposed steady-state operation scenario. A transient analysis was also carried out using a full-volume extruder dump as the worst-case scenario to determine whether the chosen pumps could handle the large gas load (3200 mbar-1/s for $30 \mathrm{sec}$ ). Peak pressures within the ballast volumes during this transient are well within the tolerable limit of 1 bar. A simulation of the ITER conceptual steady state pellet fueling system using the tritium compatible piston pump on the first stage yielded a predicted pressure of $3.3 \mathrm{mbar}$ in the first stage.

\section{ACKNOWLEDGEMENTS}

The authors would like to thank R. Sakamoto from the National Institute for Fusion Science (Japan) for the helpful discussions concerning pumping of the LHD pellet fueling system.

This work was supported by the Oak Ridge National Laboratory managed by UT-Battelle, LLC for the U.S. Department of Energy under Contract No. DEAC05-00OR22725. 


\section{REFERENCES}

[1] L. R. Baylor, P. B. Parks, T. C. Jernigan et. al., "Pellet Fuelling and Control of Burning Plasmas in ITER”, Nuclear Fusion, Volume 47, pp. 443 - 448, May 2007.

[2] A. Frattolillo, F. Bombarda, Chr. Day et. al., “An Innovative Approach for DEMO Core Fuelling by Inboard Injections of High-Speed Pellets”, Fusion Engineering and Design, Volume 124, pp. 846 - 849, March 2017.

[3] P. T. Lang, T. C. Blanken, M. Dunne et. al., "Feedback Controlled, Reactor Relevant, High-Density, High-Confinement Scenarios at ASDEX Upgrade", Nuclear Fusion, Volume 58, 036001, January 2018.

[4] L. R. Baylor, N. Commaux, T. C. Jernigan et. al., "Reduction of Edge-Localized Mode Intensity Using High-Repetition-Rate Pellet Injection in Tokamak HMode Plasmas", Physical Review Letters, Volume 110, 245001, June 2013

[5] B. Plöckl, P. T. Lang, G. Sellmair et. al., "The Enhanced High Speed Inboard Pellet Fueling System at ASDEX Upgrade”, Fusion Engineering and Design, Volume 88, pp. 1059- 1063, October 2013.

[6] S. L. Milora, S. K. Combs, and C. R. Foust, "Fast-Opening Magnetic Valve for High-Pressure Gas Injection and Applications to Hydrogen Pellet Fuelling Systems", Review of Scientific Instruments, Volume 57, pp. 2356 - 2358, September 1986.

[7] A. Géraud, M. Lennholm, T. Alarcon et. al., "Status of the JET High Frequency Pellet Injector”, Fusion Engineering and Design, Volume. 88, pp. 1064- 1068, October 2013.

[8] R. Sakamoto, H. Yamada, and LHD Expetimenta Group, "Development of Advances Pellet Injector Systems for Plasma Fueling”, Plasma Fusion and Research: Regular Articles, Volume 4, 002, 2009.

[9] S. K. Combs, L. R. Baylor, C. R. Foust, and T. C. Jernigan, “New Pellet Injection Schemes on DIII-D”, Fusion Engineering, Proceedings of the $18^{\text {th }}$ IEEE SOFE, Oct. $25-29,1999$.

[10] S. K. Combs et. al., "Operation and Reliability of a Pneumatic Hydrogen Pellet Injection System on the Joint European Torus", Fusion Engineering, Proceedings of the $13^{\text {th }}$ IEEE SOFE, Oct. $2-6,1989$.

[11] C. Runge, "Über die numerische Auflösung von Differentialgleichungen", Mathematische Annalen, Springer, Volume 46, Issue 2, pp167-178, June 1896.

[12] W. Kutta, "Beitrag zur näherungweisen Integration totaler Differentialgleichungen”, B. G. Teubner Publishing, 1901.

[13] “Fundamentals of Vacuum Technology”, leybold vacuum, 00.200.02, Kat.-Nr. 19990.

[14] L. R. Baylor, S. K. Combs, R. C. Duckworth, M. S. Lyttle, S. J. Meitner, D.A. Rasmussen, S. Maruyama, "Pellet Injection Technology and its Applications on ITER," IEEE Transactions on Plasma Science, Vol. 44, pp. 1489-1495 (2016).

[15] T. Hayashi, S. Konishi, M. Yamada, Y. Matsuda, M. Inoue, T. Nakamura, T Takanaga, Y. Naruse \& K. Okuyama, "Development of Large Oil-Free Roughing Pump for Tritium Service”, Fusion Technology, 1663-1667 (1991). 